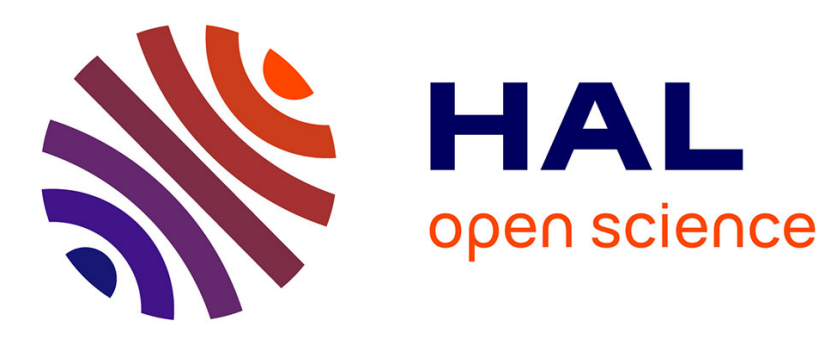

\title{
Discrete ply modelling of open hole tensile tests
}

Victor Achard, Christophe Bouvet, Bruno Castanié, Clément Chirol

\section{To cite this version:}

Victor Achard, Christophe Bouvet, Bruno Castanié, Clément Chirol. Discrete ply modelling of open hole tensile tests. Composite Structures, 2014, vol. 113, pp. 369-381. 10.1016/j.compstruct.2014.03.031 . hal-01063573

\section{HAL Id: hal-01063573 https://hal.science/hal-01063573}

Submitted on 15 Sep 2014

HAL is a multi-disciplinary open access archive for the deposit and dissemination of scientific research documents, whether they are published or not. The documents may come from teaching and research institutions in France or abroad, or from public or private research centers.
L'archive ouverte pluridisciplinaire HAL, est destinée au dépôt et à la diffusion de documents scientifiques de niveau recherche, publiés ou non, émanant des établissements d'enseignement et de recherche français ou étrangers, des laboratoires publics ou privés. 


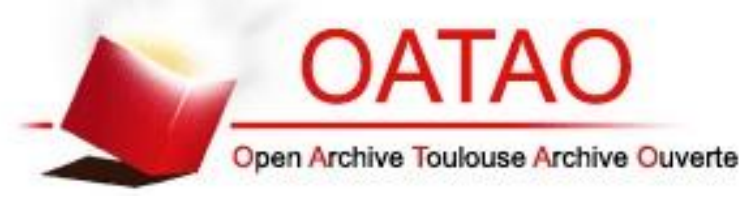

\section{Open Archive Toulouse Archive Ouverte (OATAO)}

OATAO is an open access repository that collects the work of Toulouse researchers and makes it freely available over the web where possible.

This is an author-deposited version published in: http://oatao.univ-toulouse.fr/ Eprints ID: 11985

To link to this article: DOI: 10.1016/j.compstruct.2014.03.031

URL: http://dx.doi.org/10.1016/j.compstruct.2014.03.031

To cite this version: Achard, Victor and Bouvet, Christophe and Castanié, Bruno and Chirol, Clément Discrete ply modelling of open hole tensile tests. (2014) Composite Structures, vol. 113. pp. 369-381. ISSN 02638223

Any correspondence concerning this service should be sent to the repository administrator: staff-oatao@inp-toulouse.fr 


\title{
Discrete ply modelling of open hole tensile tests
}

\author{
Victor Achard $^{\mathrm{b}, \mathrm{c}}$, Christophe Bouvet $^{\mathrm{a}}$, Bruno Castanié ${ }^{\mathrm{b}, *}$, Clément Chirol ${ }^{\mathrm{c}}$ \\ a Université de Toulouse, INSA, UPS, Mines Albi, ISAE, ICA (Institut Clément Ader), ISAE, 10 Avenue Edouard Belin, F-31055 Toulouse, France \\ ${ }^{\mathrm{b}}$ Université de Toulouse, INSA, UPS, Mines Albi, ISAE, ICA (Institut Clément Ader), INSA, 135 Avenue de Rangueil, 31077 Toulouse, France \\ ' Université de Toulouse, INSA, UPS, Mines Albi, ISAE, ICA (Institut Clément Ader), AIRBUS France, 316 Route de Bayonne, 31000 Toulouse, France
}

\section{A R T I C L E I N F O}

\section{Keywords:}

Laminate

Failure

Open-hole tensile test

Discrete modelling

\begin{abstract}
A B S T R A C T
The Discrete Ply Modelling (DPM) method, previously applied with success to out-of-plane loading such as impact or pull-through, is used to model open hole tensile tests. According to the literature, this kind of test is relevant to assess the efficiency of a modelling strategy. Four different stacking sequences are tested and the failure scenario and patterns are well predicted. The main advantages of DPM are the very small number of parameters required and the robustness of the models. The main drawback is the computation cost.
\end{abstract}

\section{Introduction}

The open hole tensile test is a challenge for the virtual testing of composites [1]. The complex failure modes and patterns described, for example in US-Mil-Hbk 17 [2], depend on many parameters, such as fibres and resin, stacking sequence, hole diameters, Width/Diameter ratios, ply thickness, and others. To correctly model this test, the approaches should be able to find the failure scenarios and, especially, to capture sub-critical damage developing before the final failure of the specimen [3]. Modelling strategies must not only be able to take account of the damage modes of laminated structures (fibre breakage, matrix cracking and splitting, delamination) and their interactions but also capture the stress gradients at the hole edge. This papers aims to apply the method of Discrete Ply Modelling (DPM), originally developed for the impact on laminates, to the open-hole tensile test. In recent years, many of the latest modelling techniques have been applied to this test case. Hu et al. [4] used it to demonstrate the effectiveness of peridynamics [5] for modelling fracture in laminates. Abisset et al [6] tested a damage meso-model on the experimental results of Hallet and Wisnom [1,3]. Despite good correlation, the authors pointed out that models based on damage mechanics have difficulties in correctly representing the splitting and intra- and inter-ply interactions otherwise than by ad hoc coefficients. This point has also been highlighted by Van der Meer and Sluys [7].

Therefore, several modelling strategies have recently been developed to better take the discontinuous nature of the damage in laminates into account. In 2008, the method of discrete ply

\footnotetext{
* Corresponding author. Tel.: +33561171172.

E-mail address: bruno.castanie@insa-toulouse.fr (B. Castanié).
}

modelling was proposed by Bouvet et al. [8] for modelling low velocity/low energy impacts on laminates stacked with unidirectional plies. A refined and complex mesh is made with an element per ply and interfaces for matrix cracking and delamination. In this way, the coupling between intra- and inter-laminar damage is naturally taken into account. Mapping areas of matrix cracking chosen a priori assumes that diffuse damage is not taken into account. Moreover, only through-the-ply cracks are assumed to be important for damage propagation. This approach predicts splitting very correctly and naturally, as was shown when it was applied to pull-through [9]. In this case, however, the edge of the hole was not correctly modelled and this point should be improved. In the latest developments of the approach, its robustness has been validated [10]. It has been extended to compression after impact [11] by a modification of the breaking law of fibre in compression. Finally, by considering the non-closure of matrix cracks, permanent indentation after impact can be calculated [12]. This type of discrete modelling has also been used by Wisnom and Hallet [1] to model the failure of open-hole specimens. However, in this first approach, the paths of possible failures are limited.

Other researchers have tried to take account of the discrete nature of the damage of composite structures. Prabhakar and Waas [13] propose a triangular finite element enabling matrix crack failure by a splitting of the element in two parts. The approach has been validated on open-hole tensile test specimens fully oriented at $90^{\circ}, 45^{\circ}$ or $0^{\circ}$. This stacking limits the scope of the approach for the moment but, nevertheless, the use of elements enabling splitting is developing. Most of the very recent approaches are based on XFEM [14]. Van der Meer [15,16] uses phantom node elements (a variation on XFEM) to model matrix cracking. Associated with cohesive elements for delamination, this method eliminates 
the complexity of the mesh of DPM. This method has also been validated on open-hole tensile tests performed by Wisnom and Hallet [3]. Recently this approach has been extended to the representation of diffuse damage [17]. Iarve, Swindeman et al. [18-20] used regularized X-FEM, which differs from the previous approach by interpolation functions that are based on the integration of the initial Gauss scheme. According to the authors, the cracks remain "encapsulated" within the element and this provides a straightforward three-dimensional implementation. Once again, the open tensile test was used for validation and very good correlation was found with this approach. An analysis of the recent literature shows that recent research has been strongly oriented towards discrete numerical methods for modelling failures in laminates.

In this paper, open hole tensile tests are performed with four different stacking sequences and are analysed by means of the DPM method. The following section gives details of the tests and samples. Then DPM is presented and compared with experimental results. Failure scenarios and the influence of the position of the $0^{\circ}$ plies are discussed.

\section{Experimental analysis}

The specimens were made from layers of unidirectional, intermediate modulus carbon/epoxy prepreg composites. Four types of stacking sequences were studied and are given in Table 1 . Two laminates were highly oriented at $0^{\circ}$ and the other two were quasi-isotropic with a different layout in thickness. The second orientation was obtained by cutting at $90^{\circ}$ from the first. The choice of these layups was based on "benchmark" industrial laminates. The thicknesses ranged from $1.1 \mathrm{~mm}$ to $2.6 \mathrm{~mm}$. The layups Iso-Q 1 , Q 2 -Iso-, oriented 1 and 2 were draped with 0.13 -mm-thick plies and layup Oriented 1 was draped with 0.18 -mm-thick plies.

The specimen geometry is given in Fig. 1, where the dimensions are in $\mathrm{mm}$. A 4.2-mm hole was drilled at the centre. The machining quality was guaranteed by the use of new carbide tooling, with a sacrificial plate affixed and tightened on each side of the laminate to limit the damage (particularly delamination). The machining quality was verified by X-ray and no damage induced during drilling was found. The edges of the specimens were trimmed using a diamond disc. The absence of damage on the edges was checked with the aid of a binocular. Local reinforcement, made of 4 fibreglass plies at $0^{\circ}$, was bonded to the specimen. The quasi-static tests were performed at a speed of $1 \mathrm{~mm} \cdot \mathrm{min}^{-1}$ on a $100 \mathrm{kN}$ Instron machine at ambient temperature and humidity (Fig. 2). The hole deformation was measured by an Instron extensometer fixed symmetrically to the median planes of the test specimens (Fig. 2). The forces applied were measured by the load cell of the machine.

Three tests were performed up to final failure for each layup. The dispersion found (CV) on the reference specimens was low $(<4 \%)$ but, for the open-hole specimen, it was very low $(<1 \%)$. It seems that the presence of the hole had the effect of reducing the variance. The moduli also showed little dispersion ( $<3 \%)$. The stress/strain experimental responses are plotted in Fig. 3. For each layup, the stresses were normalized. The four laminates had fairly

Table 1

Laminate stacking sequences.

\begin{tabular}{llll}
\hline Laminate & Lay up & $\begin{array}{l}\text { Number } \\
\text { of plies }\end{array}$ & $\begin{array}{l}\text { Overall } \\
\text { thickness } \\
(\mathrm{mm})\end{array}$ \\
\hline Oriented 1 & $\begin{array}{l}{[-45 / 0 / 0 / 45 / 0 / 90 / 45 /-45 / 90 / 0 / 45 / 0 /} \\
0 /-45]\end{array}$ & 14 & 2.6 \\
Oriented 2 & {$[45 /-45 / 0 / 0 / 90 / 0 / 0 /-45 / 45]$} & 9 & 1.143 \\
Q-isotropic 1 & {$[0 / 45 / 90 /-45]_{2 \mathrm{~s}}$} & 16 & 2.1 \\
Q-isotropic 2 & {$[90 /-45 / 0 / 45]_{2 \mathrm{~s}}$} & 16 & 2.1 \\
\hline
\end{tabular}

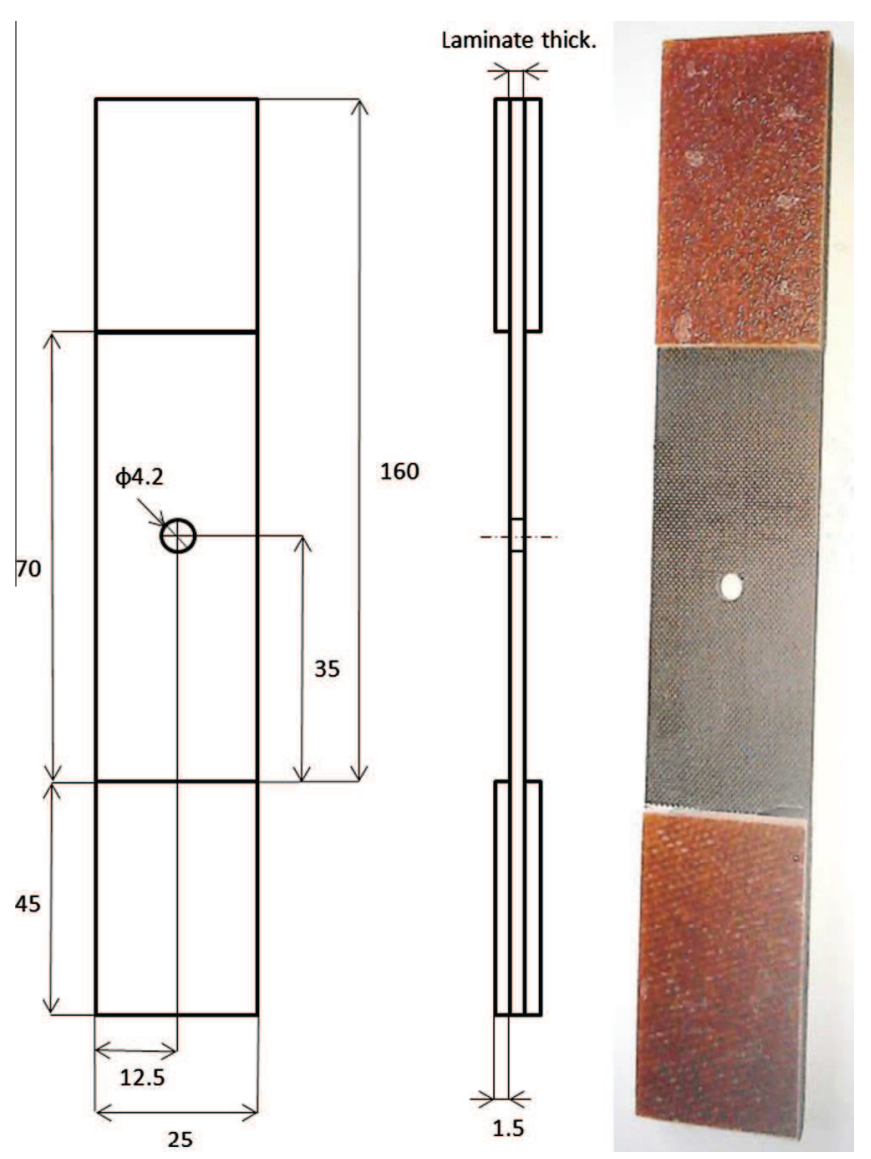

Fig. 1. Specimen description.

equivalent behaviour: a first linear response without apparent loss of rigidity followed by a chaotic plateau showing a series of damage events before final failure of the specimen. The sharp drop in force that occurred at the end of the plate is not shown on these curves because the extensometer could not capture it. For highly oriented specimens 1 , the plateau was short. If structural failure is defined as the first occurrence where a load drop of more than $5 \%$ is recorded in a quasi-static test [9], the dispersion is very small (about $1 \%$ ). Failure patterns and X-ray analyses that were performed on stopped tests are presented in the model validation subsection.
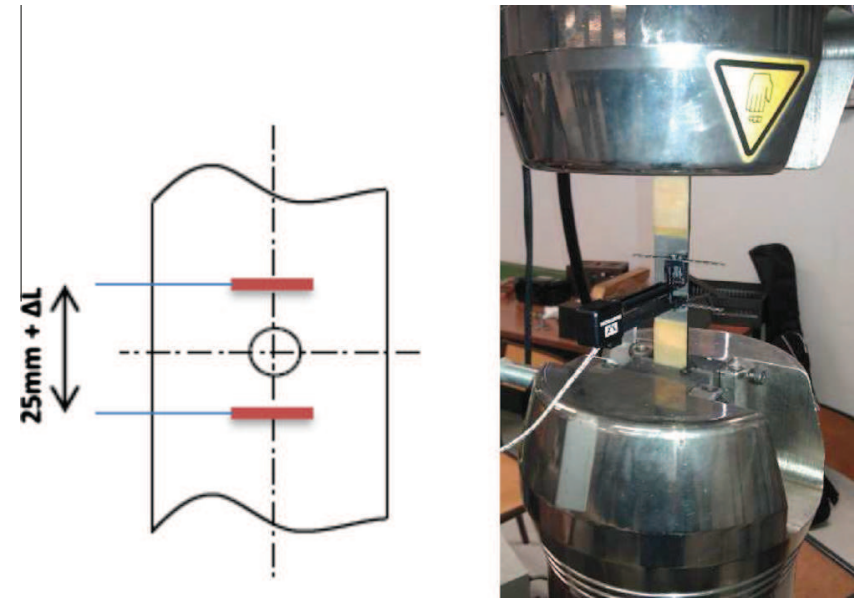

Fig. 2. Position of the extensometer on tensile specimen and view of the test. 

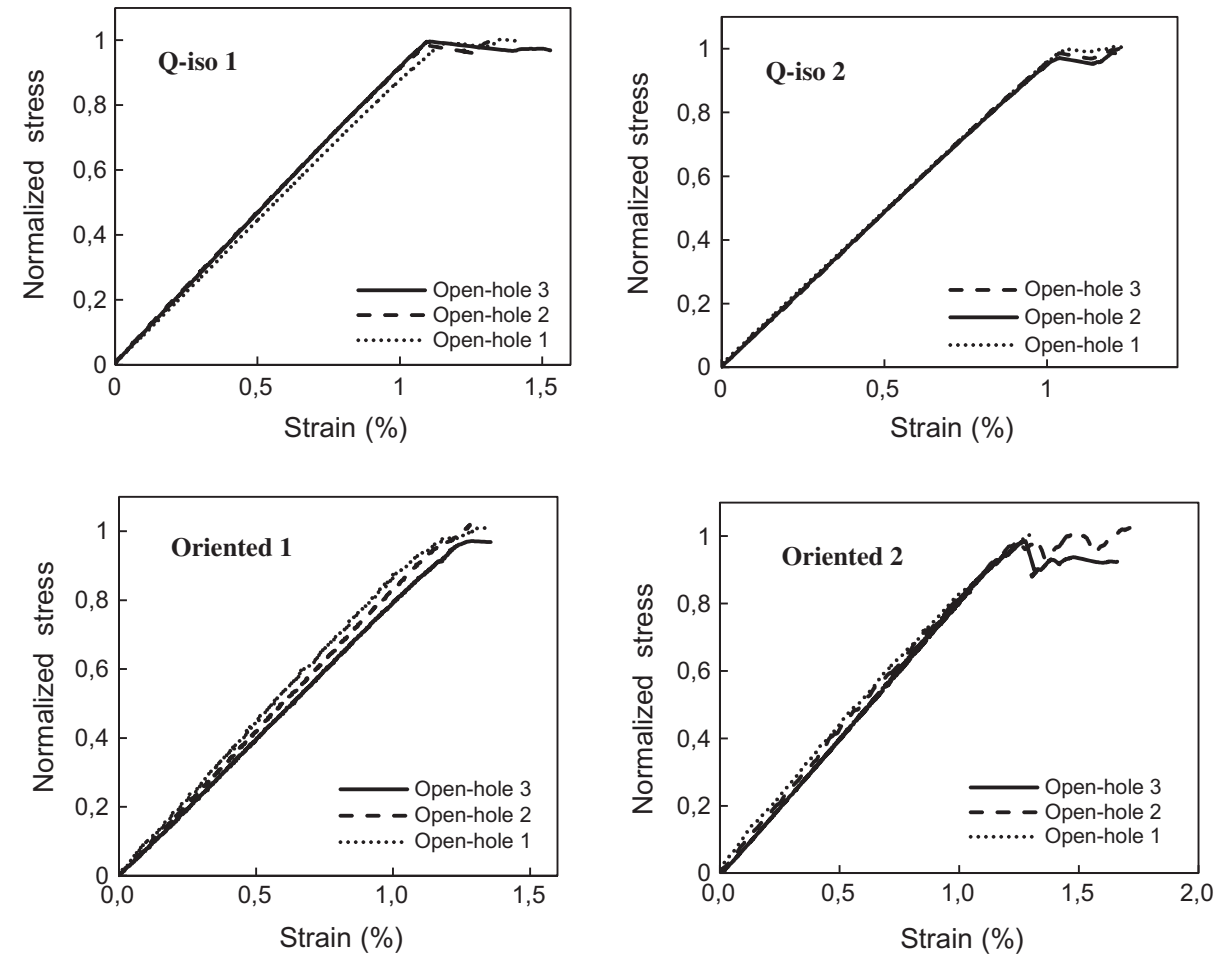

Fig. 3. Tension behaviour of the four types of open-hole specimens.

\section{Numerical modelling}

The DPM approach has already been explained in several papers [8-12] and only its general principles and its adaptation to the current problem are presented here. In their first paper, Bouvet et al. [8] presented a discrete 3D impact model which was simulated with the Abaqus v6.9 explicit solver and a user-defined Vumat subroutine. In their model, three major failure modes observed in composite impact tests were considered: (i) fibre failure in intraply, (ii) matrix cracking in intra-ply, and (iii) delamination in inter-ply. The mesh construction from their previous work was maintained (Fig 4(a)). The nodes were uniformly stacked in rows and columns for all oriented plies. However, the shapes of the mesh were different: $0^{\circ}$ and $90^{\circ}$ plies were meshed in a square shape, while $45^{\circ}$ and $-45^{\circ}$ plies were meshed in a parallelogram shape in order to follow the fibre direction and to have coincident nodes in adjacent plies (Fig. 4(b)). The fibre failure was assigned to volume elements C3D8, with zero-thickness cohesive elements of delamination, COH3D8, horizontally inserted between them. Also, vertical zero-thickness cohesive elements COH3D8 were placed between volume element strips in the fibre direction to impose the region of matrix cracking, as shown in Fig. 4(a).

The presence of a hole required an adaptation of the in-house meshing program. In [9], the representation of the hole was very poor. However, it did not impact the structural response because of the pull-through loading. For the problem of the open hole tensile test, a good representation of the hole was a prerequisite. Practically, this good representation was obtained by a projection of the nodes adjacent to the hole. If the node/perimeter distance was less than the size of an element, the node was generated and projected on the theoretical perimeter. Otherwise, it was not created. The direction of projection depended on the principal direction of the fold considered in order to maintain the parallelism between slices of matrix cracking elements. In this way, an acceptable model of the hole was obtained (see Fig. 5). In the plies, the method required

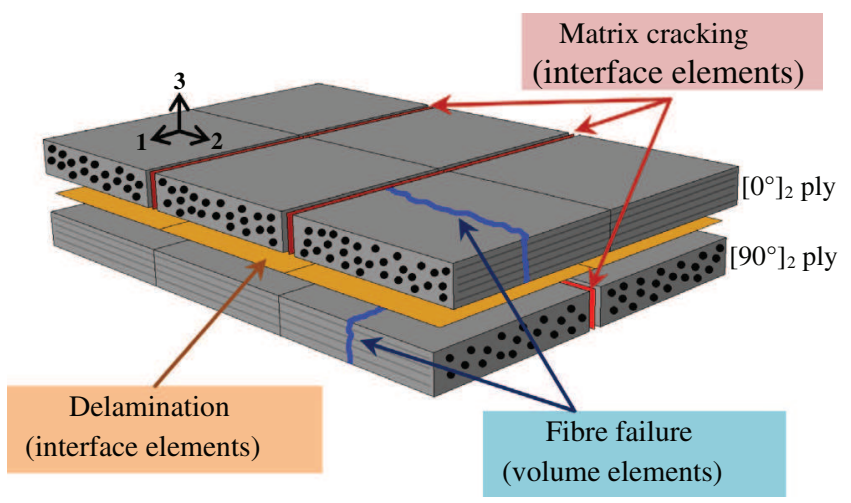

(a)
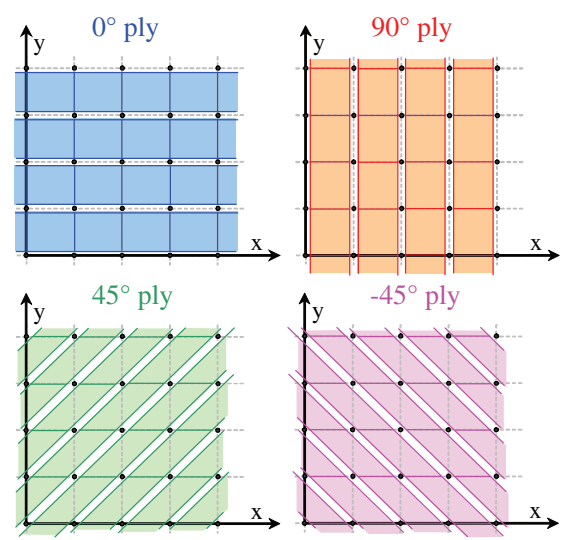

(b)

Fig. 4. (a) Modelling of impact damage and element types and (b) mesh shape in each oriented ply. 
the creation of several triangular elements near the hole edge (and some quadrangles), which could be distorted according to the discretization imposed. The delamination elements were subsequently created between adjacent plies. Near the hole, according to the mesh size and the size of the hole, some elements of delamination could be very small and distorted, creating numerical problems, so these elements were simply removed. For the specimens used in the present study, after a convergence study, the size of the elements was chosen as $0.32 \times 0.32 \mathrm{~mm}^{2}$, leading to a total number of elements between 130,000 and 430,000 according to the number of plies (see Fig. 5).

\subsection{Modelling of matrix cracking}

As previously mentioned, the matrix cracking is taken into account using vertical non-thickness interface elements between 2 consecutive volume elements (Fig. 4a). Then the interface degradation is rough: if the material is safe, the stiffnesses of these matrix cracking interfaces are considered very high (typically $10^{6} \mathrm{MPa} /$ $\mathrm{mm}$ ) and these stiffnesses are put to zero if matrix crack exists. And this failure is driven thanks to standard failure criterion, similar to Hashin's criteria [21], evaluated in the neighbouring volumic elements:

$\left(\frac{\left\langle\sigma_{t}\right\rangle^{+}}{Y^{T}}\right)^{2}+\frac{\tau_{l t}^{2}+\tau_{t z}^{2}}{\left(S^{L}\right)^{2}} \leqslant 1$

where $\sigma_{t}$ is the transverse stress, $\tau_{l t}$ and $\tau_{t z}$ the shear stresses in the $(l t)$ and $(t z)$ planes, \langle\rangle$^{+}$is the positive value, $Y^{T}$ is the transverse failure stress and $S^{L}$ is the shear failure stress of the ply. In fact, this classical quadratic criterion was written with stresses at each Gauss point of the 2 neighbouring volume elements and the interface was broken when the criterion was reached at one of these points.

\subsection{Modelling of fibre failure}

As the critical energy release rate is high at fibre failure [22], it was necessary to dissipate this energy in the model. Additional interface elements could have been used but would have induced very complex meshing. To avoid using such interfaces, fibre failure was taken into account through classical continuum damage mechanics but with an original formulation between the integration points of the element to dissipate a constant energy release per unit area. This approach can be compared to the methods with characteristic element length that allow modelling to be independent of the mesh size $[23,24]$.

Then, in order to be able to dissipate the critical energy released due to fibre fractures per unit area of crack, the behaviour laws of the 8 integration points of a volume element were driven together. In this case, the law was written only in opening mode I (Fig. 6), but could be generalized to other fracture modes:

$\int_{V}\left(\int_{0}^{\varepsilon_{I}^{T}} \sigma_{l} \cdot d \varepsilon_{l}\right) \cdot d V=S \cdot G_{I c}^{\text {fibre } t}$

where $\sigma_{l}\left(\varepsilon_{l}\right)$ is the longitudinal stress (strain), $V(S)$ is the volume (section) of the element, $\varepsilon_{I}^{T}$ is the strain of total degradation of the fibre stiffness (Fig. 6) and $G_{I C}^{\text {fibre, } t}$ is the energy release rate in opening mode in the direction of the fibres. It can be noted that volumic elements with 8 Gauss points have been chosen to obtain a good bending behaviour with only one element in the ply thickness.

Afterwards, the stiffness in the direction of the fibres was degraded by means of a damage variable $d_{f}$ :

$\sigma_{l}=\left(1-d_{f}\right) \cdot\left(H_{l l} \cdot \varepsilon_{l}+H_{l t} \cdot \varepsilon_{t}+H_{l z} \cdot \varepsilon_{z}\right)$

where $H_{l l}, H_{l t}$ and $H_{l z}$ are the stiffnesses in the longitudinal direction. This damage variable is classically evaluated using the longitudinal strain in order to obtain a linear decrease in the longitudinal stress (Fig. 6):

$d_{f}=\frac{\varepsilon_{I}^{T} \cdot\left(\varepsilon_{l}-\varepsilon_{0}^{T}\right)}{\varepsilon_{l} \cdot\left(\varepsilon_{I}^{T}-\varepsilon_{0}^{T}\right)}$

where $\varepsilon_{I}^{T}$ is the strain of total degradation of the fibre stiffness evaluated from Eq. (2) and $\varepsilon_{0}{ }^{T}$ is the strain of damage initiation.

Moreover, fibre failure due to compression or shear stresses is not taken into account in this release of the model since it is based on reference cases where these types of fibre failure do not seem to appear. Nevertheless, these failure types could be taken into account for other tests, as in fibre failure under compressive loading for compression after impact [11].

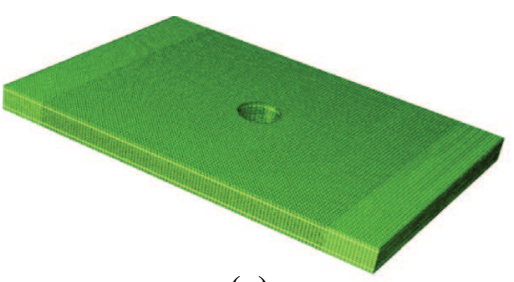

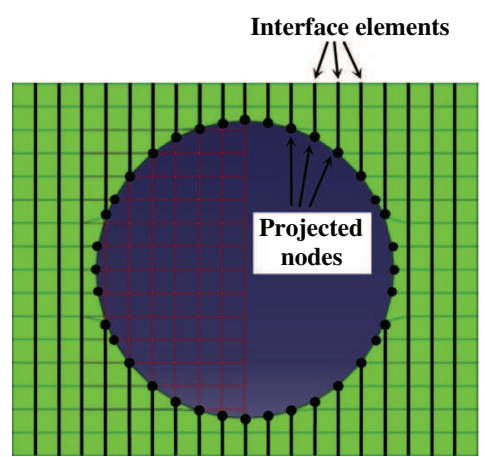

(b)

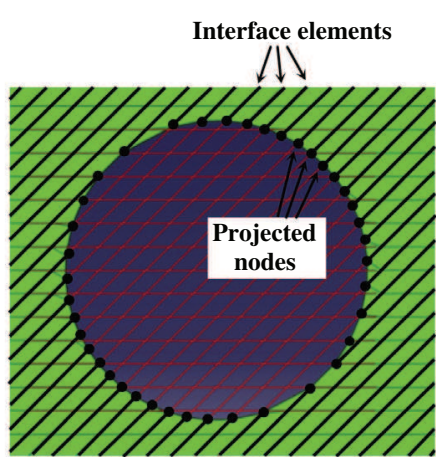

(c)

Fig. 5. (a) Discrete ply modelling of an open hole specimen (a) global view, (b) $0^{\circ}$ ply, and (c) $45^{\circ}$ ply. 


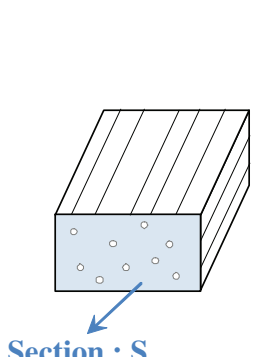

(a)

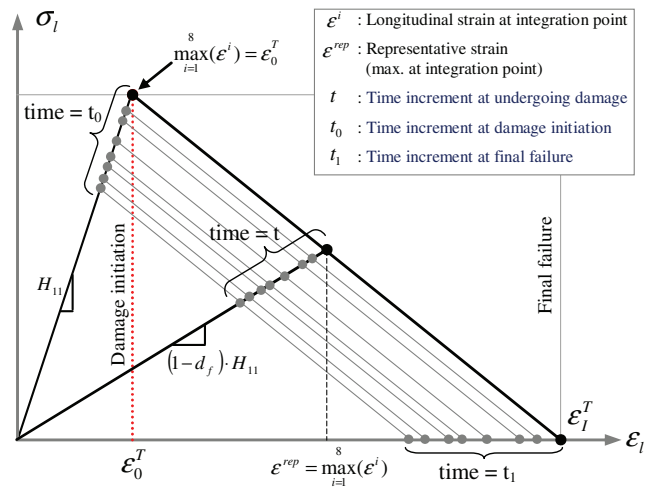

(b)

Fig. 6. Principle of fibres failure (a) and behaviour law in the longitudinal direction (b).

\subsection{Modelling of delamination}

The formation of delamination is generally related with matrix cracking. For the present discrete modelling, even if there is no parameter coupling delamination and matrix cracking, the discontinuity still allows this interaction to take place. Delamination normally occurs between differently oriented plies. It was therefore simulated in interface elements, joining nodes of lower and upper volume ply elements. Through the energy dissipation of fracture mechanics, the criterion of delamination was simulated as linear coupling in three modes based on a power law criterion of mixed-mode delamination propagation with the energy release rate: mode $I$ was in the thickness direction normal to the delamination plane, while mode II and mode III were in the in-plane direction:

$\frac{G_{I}}{G_{I c}^{\text {del }}}+\frac{G_{I I}}{G_{\text {IIC }}^{\text {del }}}+\frac{G_{I I I}}{G_{\text {IIIC }}^{\text {del }}}=1$

where GI, GII, GIII are the energy release rate of delamination in

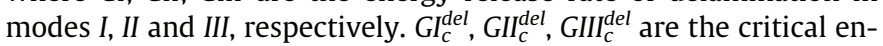
ergy release rates of delamination in modes $I$, II and III, respectively. Moreover, the modes II and III are supposed to be equal $\left(\right.$ GII $_{c}^{d e l}=$ GIII $_{\bar{c}}$ $\left.{ }^{d e l}\right)$. In this case, the material parameters needed for modelling are given in Table 2. Only five elastic characteristics and 8 parameters related to failure are required. The values of these material parameters come from classical experimental tests from the literatures $[22,25-27]$.

\section{Model validation and discussion}

Model validation will be performed by comparing the experimental results and the DPM computation in terms of stress vs. strain responses, post-mortem failure patterns and damage maps at structural failure. Then, a detailed analysis of failure scenarios for the four layups will be proposed and the influence of the position of the $0^{\circ}$ plies in the thickness will be discussed. The calculation was performed with Abaqus explicit. After a sensitivity study, the rate of application of the load was set at $0.25 \mathrm{~m} \mathrm{~s}^{-1}$. The computation time was then spread over a period ranging from 30 to $200 \mathrm{~h}$ on 8 CPUs.

\subsection{Model validation}

Stress/strain responses are compared in Fig. 7 for all laminates. The comparison in the elastic part is, of course, very acceptable for all layups. In terms of ultimate tensile stress (UTS), the error varies between 2.8\% (Oriented 1) and 8\% (Q-1 Iso). Therefore, the model
Table 2

Material properties.

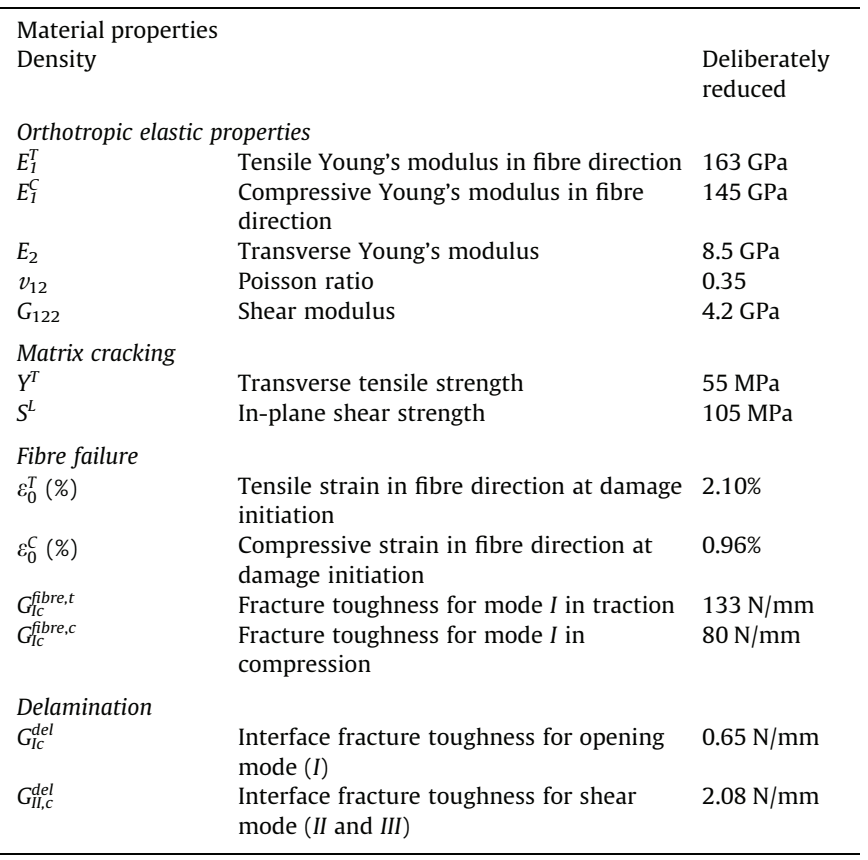

captures the final rupture modes well. However, the model has some difficulty in following the plateau. Two examples of final failure patterns are given in Figs. 8 and 9 and the computation of the damage at this step is also shown. For the first example (quasi-isotropic 2), the failure occurs along a line at $45^{\circ}$ (Fig. $8(\mathrm{a})$ ). This line corresponds to the cracked area of the matrix in the $0^{\circ}$ ply (Fig. 8(b)), together with a narrow region of delaminated interface between the $0^{\circ}$ ply and the adjacent ply at $45^{\circ}$ (Fig. 8(c)). It is also interesting to note that the zone of fibre failure captured by the model is also at $45^{\circ}$ (Fig. $8(\mathrm{~d})$ ), which corresponds well with the observed line break. In the second case, corresponding to thick oriented layup 1, the failure is more complex. The failure pattern is shown in Fig. 9(a). The breakages of the $0^{\circ}$ ply are very disordered but is also consistent with the results of DPM modelling (Fig. 9(c)). In the two $0^{\circ}$ plies, according to the computation, at UTS, splitting occurs everywhere (Fig. 9(d)), which is also consistent with some aspects of the final failure pattern. Delaminations are visible at the edges of the specimen (Fig. 9(b)) and correspond to [0/90] 


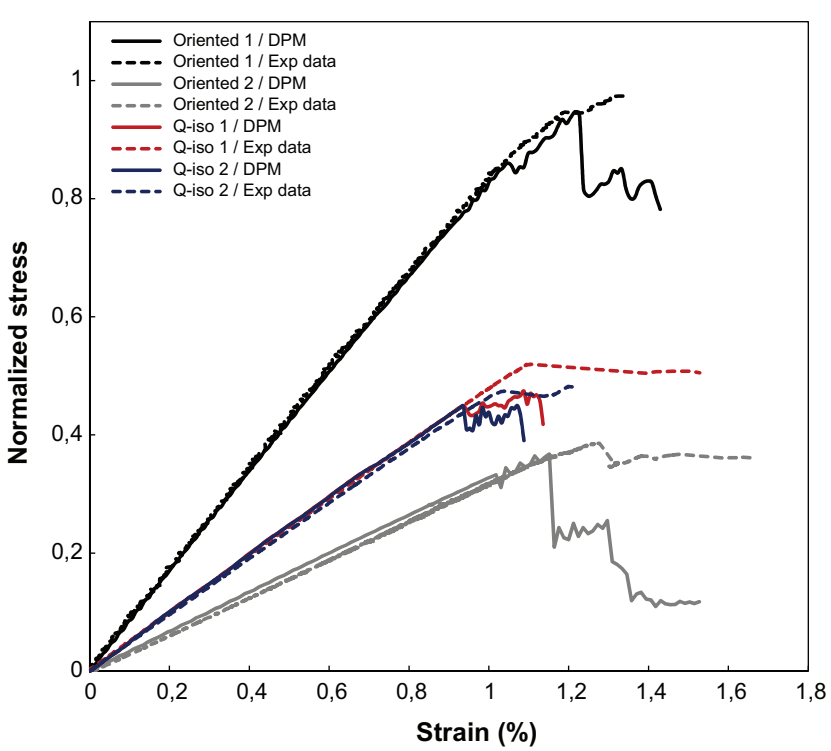

Fig. 7. DPM comparison with experimental stress/strain relations.

interfaces which, according to the DPM computation (Fig. 9(e)), are also completely delaminated. As the final failure of this laminate is explosive, dynamic phenomena may have occurred and randomized the fracture surface of the $0^{\circ}$ plies. Nevertheless, globally, the model predicts the final pattern correctly.

The comparison in terms of matrix cracking is shown in Fig. 10 at structural failure. Analysis of the quasi-iso 2 laminates could not be performed due to lack of material. In all cases, the X-ray analysis highlights the main splits very clearly. It is probable that the secondary cracks closed because of a certain plasticity provided by the high proportion of thermoplastic phase in the resin used, which prevented revealing liquid from penetrating sufficiently into small cracks. The comparison is thus primarily qualitative. The main splitting at $0^{\circ}$ for oriented laminates is correctly captured by the model in terms of location and size of cracks (in the range of $8-14 \mathrm{~mm}$ ). A zoom on the photos also showed cracking at $45^{\circ}$ for these laminates, in particular for the first oriented layup. For the quasi-iso laminates, the dense matrix cracking zone near the hole is captured. The main $45^{\circ}$ splits are also found. We can therefore consider that, globally, the model is able to represent the matrix cracking state at structural failure.

In conclusion, direct application of the DPM approach allows the tensile behaviour of open hole specimens to be correctly represented up to failure. In the next subsection, the rupture scenario and the importance of the position of the $0^{\circ}$ plies with this model will be discussed for the four laminates.

\subsection{Discussion of failure scenario and $0^{\circ}$ ply location}

When laminated specimens are subjected to tension, the structural and ultimate failures are related to the state of damage of the $0^{\circ}$ plies. Other plies are often already severely damaged without visible loss of stiffness on the stress/strain curves. However, for laminates with open holes, Hallet et al. [1] have shown that this so-called sub-critical damage influences the failure mode of the laminate (brittle, pull-out or delamination) and finally the ultimate load level. In this study, the evolution of sub-critical damage was essentially identical for the four layups. However, they could be influenced by the presence or absence of splitting in the $0^{\circ}$ plies.

In Fig. 11, the evolution of matrix cracking is shown for a $90^{\circ}$ ply (column 1 ), a $45^{\circ}$ ply (column 2 ) and a $45^{\circ}$ ply with an adjacent $0^{\circ}$ ply which splits (column 3). Rapid growth of the cracking in the plies at $90^{\circ}$ and $\pm 45^{\circ}$ is noted first. This cracking is particularly severe in the $90^{\circ} \mathrm{ply}$, in which the damage propagates rapidly from the hole edge in a butterfly-wing pattern. Then, cracks appear at the free edge and the ply is almost completely damaged before UTS. The DPM modelling shows that this mode of damage of the $90^{\circ}$ ply is almost identical for the four configurations and thus independent of adjacent plies. Regarding cracking in the $\pm 45^{\circ}$ plies (Fig. 11), we note that it spreads transversely along the specimen, from the hole edge to the free edges, generating a characteristic "X" pattern (columns 2 and 3). This type of damage has already

Quasi-iso 2

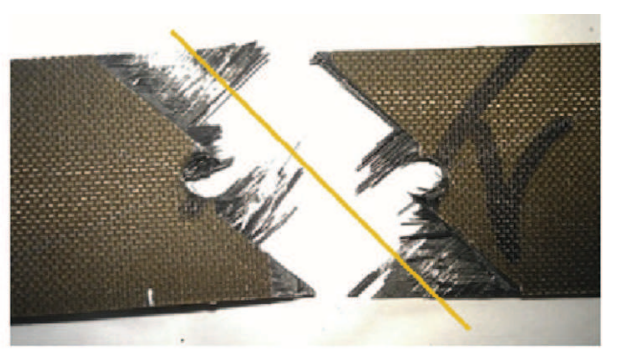

(a)

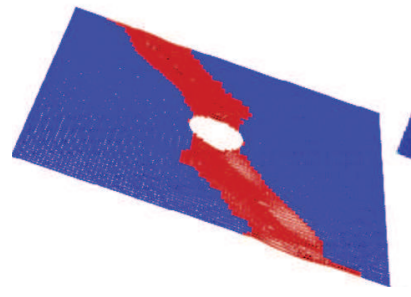

(b)

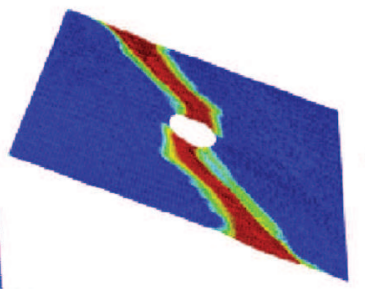

(c)

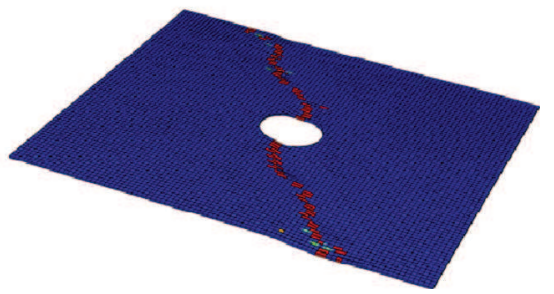

(d)

Fig. 8. Comparison of failure pattern at UTS for quasi-iso 2 layup $[0 / 45 / 90 /-45]_{2 \mathrm{~s}}$ (a) bottom view, (b) matrix cracking, (c) delamination in $0^{\circ} / 45^{\circ}$ interface, and (d) fibre failure in outer $0^{\circ}$ ply. 
(a)

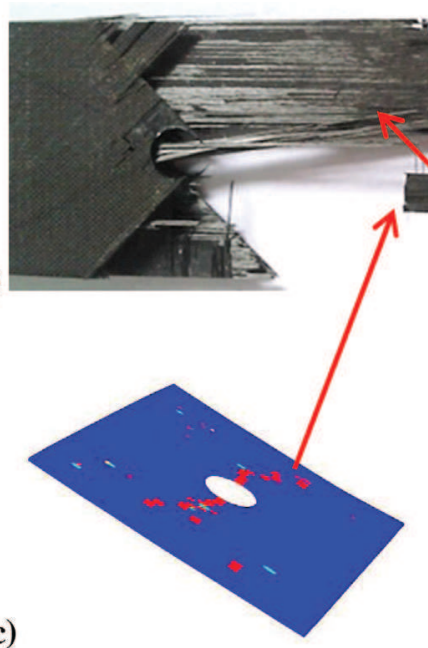

(d)

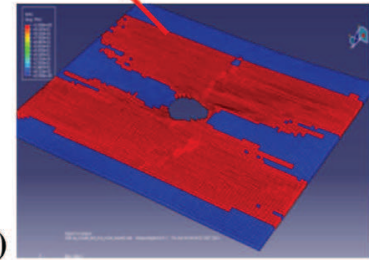

(b)

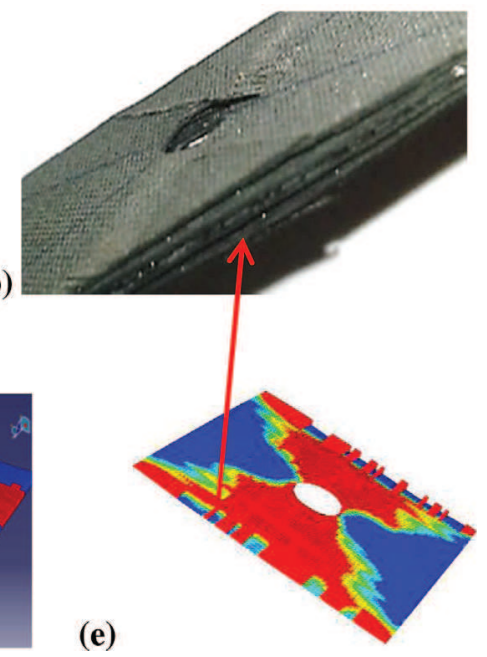

Fig. 9. Comparison of failure pattern at UTS for Oriented 2 layup [45/-45/0/0/90/0/0/-45/45] (a) bottom view, (b) side view, (c) fibre failure in [0 $\left.0_{2}\right]$ plies, (d) matrix cracking in $\left[0_{2}\right]$ plies, and (e) delamination at $[0 / 90]$ interface.

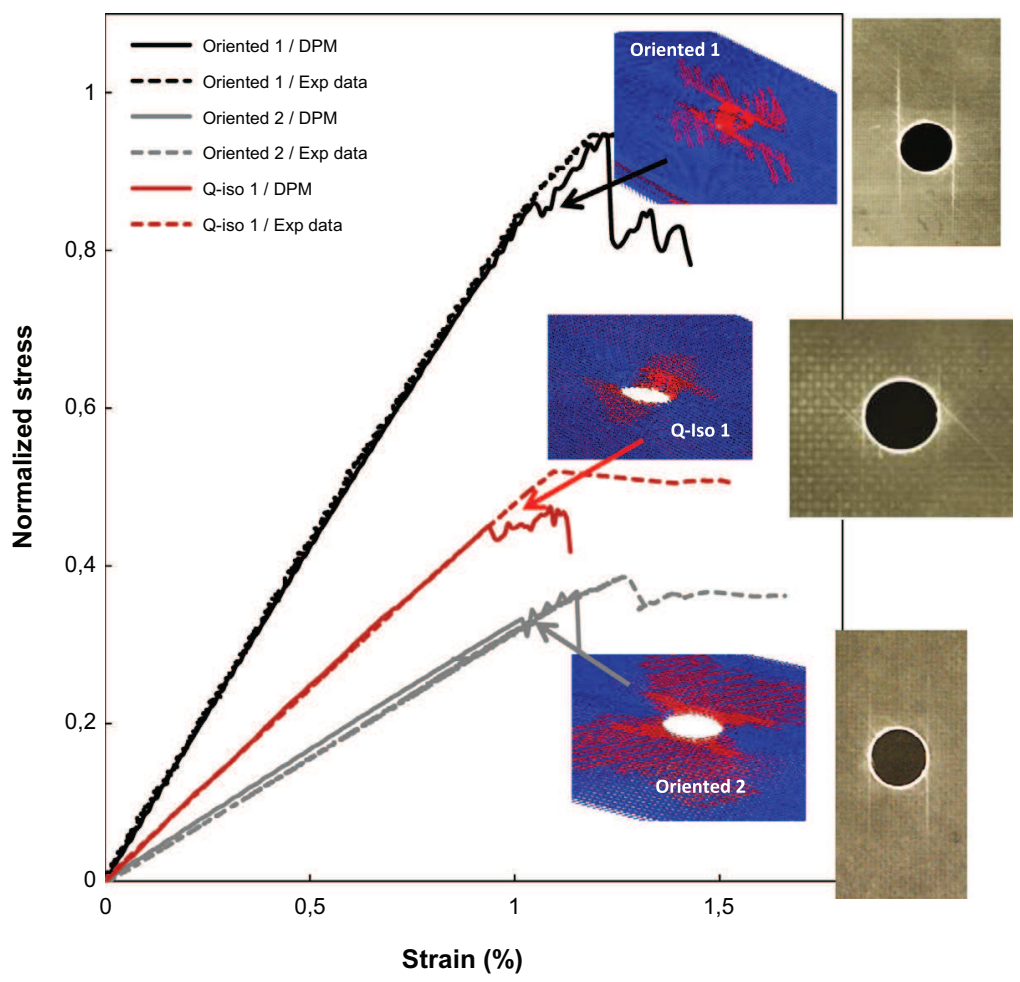

Fig. 10. DPM matrix cracking comparison with experimental X-ray at structural failure.

been found in the literature [6]. However, when the ply at $45^{\circ}$ is not adjacent to a ply at $0^{\circ}$, the propagation is diffuse (Fig. 11 , column 2 ). Where a $0^{\circ}$ ply is adjacent to a $45^{\circ}$ ply (Fig. 11 , column 3 ), the propagation is much more rapid and also more discrete. This difference in behaviour can be attributed to the splits in the $0^{\circ}$ plies, which are also discrete but will change the distribution of local stresses and interact with the adjacent $45^{\circ}$ ply, thus influencing the final pattern of cracking at $45^{\circ}$.

Therefore, it is now timely to consider the different modes of damage in the $0^{\circ}$ plies that lead to the final failure. In the following subsections, damage to plies adjacent to $0^{\circ}$ plies will not be presented again. Positions of the $0^{\circ}$ plies are very different in the 4 different laminates of the industrial benchmark (Fig. 12). In cases A, B,
$\mathrm{D}$ and $\mathrm{G}, 0^{\circ}$ plies are inside the material, in case $\mathrm{C}$, the $0^{\circ}$ ply is on the surface and, in cases $\mathrm{E}$ and $\mathrm{F}$, the thickness is doubled. The easiest scenario to analyse (quasi-isotropic 2 ) will be presented first and the most complex (Oriented 1) last, following the order used in Fig. 12.

\subsubsection{Failure scenario of quasi-isotropic 2 laminate}

The $0^{\circ}$ plies studied in this laminate (type A or B, Fig. 12) are internal and their interfaces are the same $\left(-45^{\circ} / 0^{\circ} / 45^{\circ}\right)$. The cracking pattern of $45^{\circ}$ and $90^{\circ}$ is similar to those given previously in Fig. 11 and is not recalled here. Damage in the $0^{\circ}$ ply is shown in Fig. 13. Matrix cracking in the $0^{\circ}$ plies begins early but does not propagate and remains confined to one or two bands of elements 


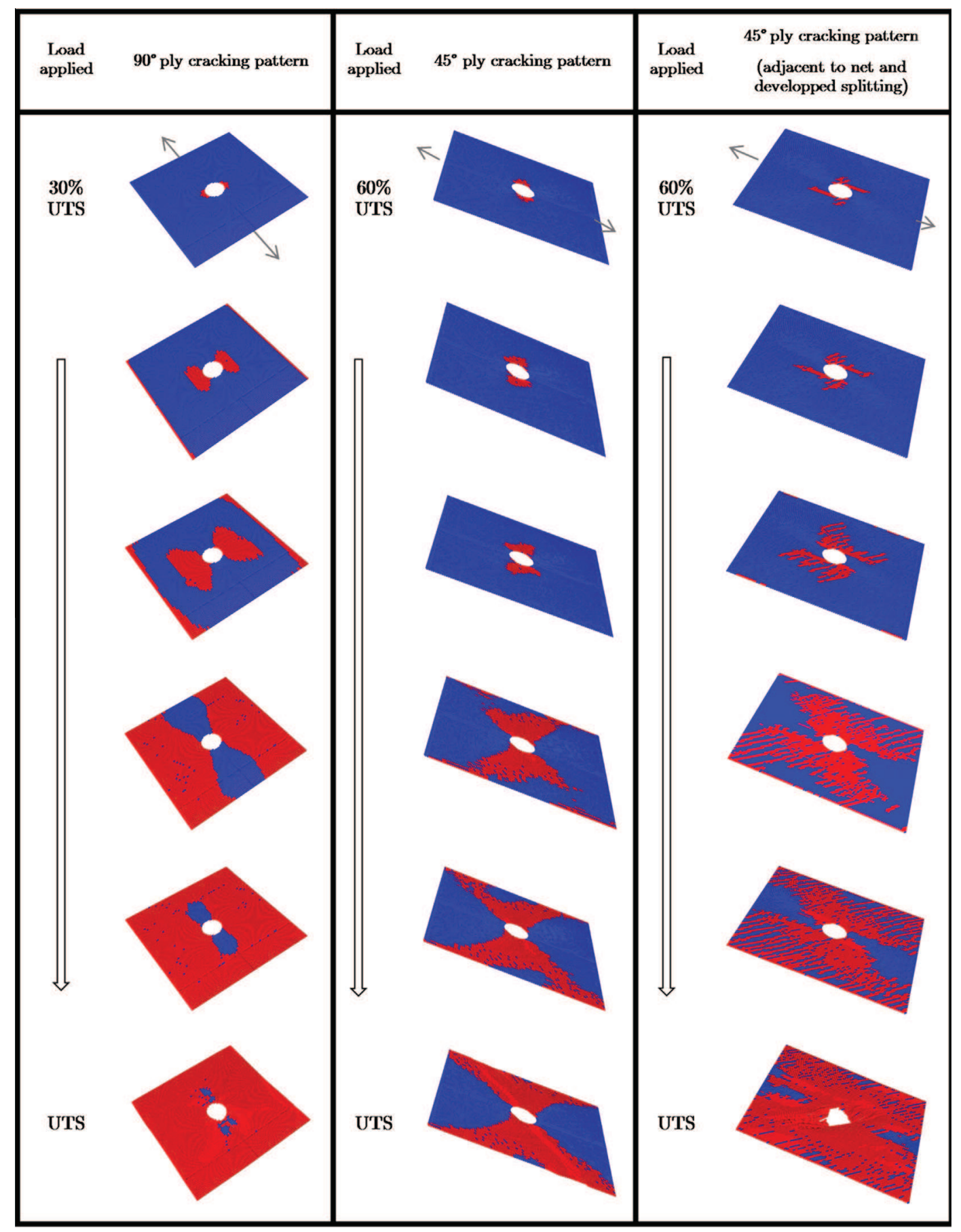

Fig. 11. Matrix cracking in $90^{\circ}$ plies (column 1 ), $45^{\circ}$ plies (column 2 ) and $45^{\circ}$ with splitting in the adjacent $0^{\circ}$ ply.

at the hole edge. When the load increases, there is first a brutal propagation of the cracked area of the matrix in conjunction with the first fibre failures. Simultaneously, delamination occurs in a similar shape in the $0^{\circ} / 45^{\circ}$ and $45^{\circ} / 90^{\circ}$ interfaces. This damage creates a sufficient loss of stiffness to be identified as structural failure. At this stage, approximately $12 \%$ of the net section is broken. Beyond this limit, simultaneous progressive propagation of the different types of damage is observed at an angle of $45^{\circ}$. The damaged area is confined to a relatively narrow band (Fig. 13). Finally, the area of broken fibres reaches the free edges, generating the final failure of the specimen. Computation also shows that matrix cracking in the $0^{\circ}$ ply takes place before delamination, as is the

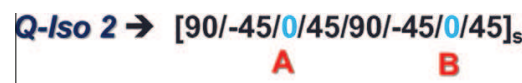

Q-Iso $1 \rightarrow[0 / 45 / 90 /-45 / 0 / 45 / 90 /-45]_{\mathrm{s}}$

C

Oriented $2 \rightarrow[45 /-45 / 0 / 0 / 90 / 0 / 0 /-45 / 45]$

E

Oriented $1 \rightarrow[45 / 0 / 0 /-45 / 0 / 90 /-45 / 45 / 90 / 0 /-45 / 0 / 0 / 45]$

F

G

Fig. 12. Position of the $0^{\circ}$ ply in different layups 


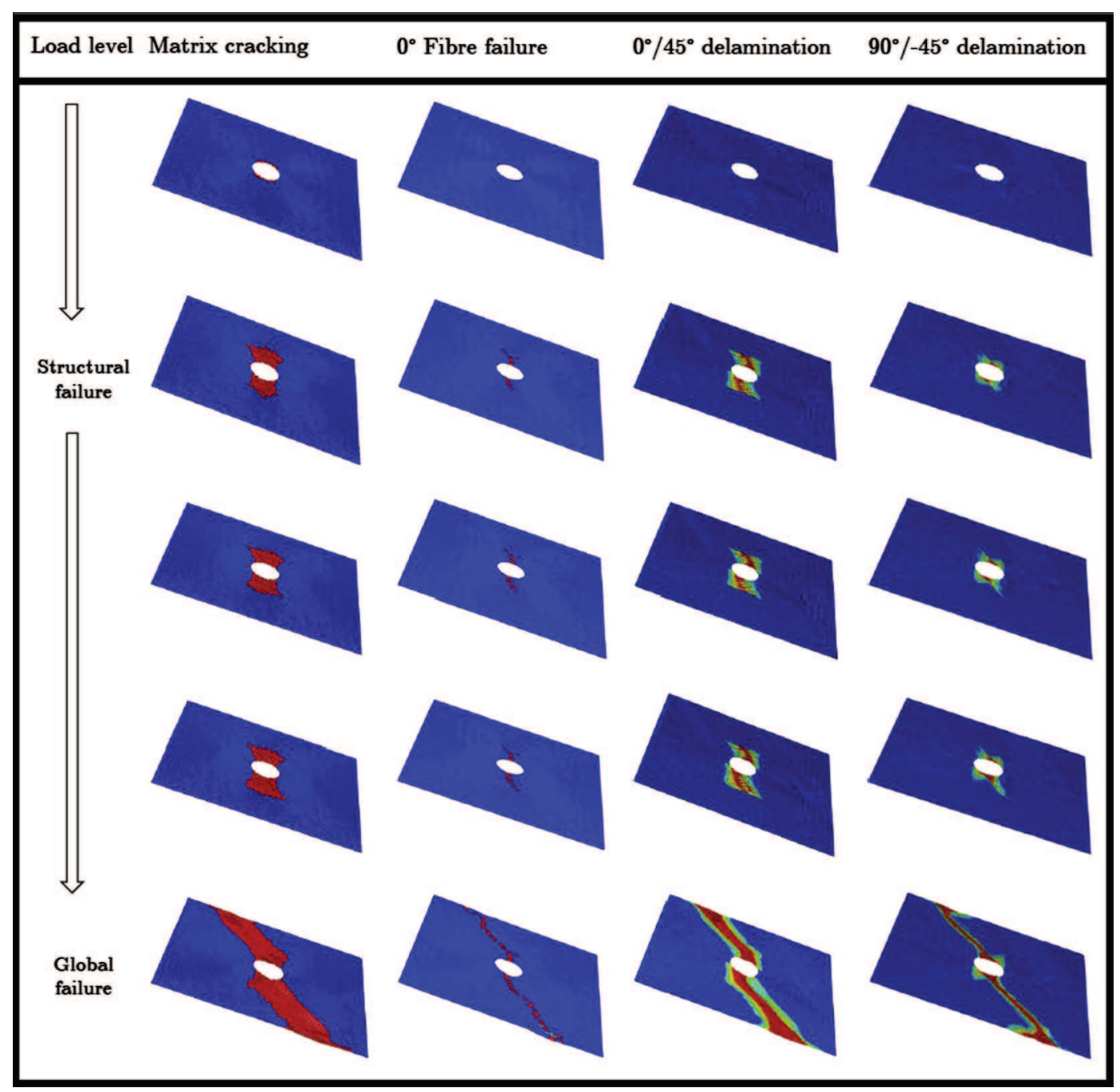

Fig. 13. Failure scenario for q-iso 2 . Columns 1 and 2 respectively: matrix cracking and fibre failure in $0^{\circ}$ ply. Columns 3 and 4 respectively: delamination at interfaces $0^{\circ} / 45^{\circ}$ and $90^{\circ} /-45^{\circ}$.

case for impact behaviour of laminates, and thus drives the delamination propagation.

\subsubsection{Failure scenario of quasi-isotropic 1 laminate}

In this laminate, a $0^{\circ}$ ply is internal (see D, Fig 12) and its adjacent interfaces are identical to the configurations $\mathrm{A}$ and $\mathrm{B}\left(-45^{\circ} / 0^{\circ}\right.$ $45^{\circ}$ ). Another $0^{\circ}$ ply is stacked at the external surface (see C, Fig. 12) with a single $0^{\circ} / 45^{\circ}$ interface. The DPM computation shows that the damage process in internal ply $\mathrm{D}$ is identical to that in plies $A$ and $B$. The damage evolution of ply $C$ and fibre failure of the inner ply, D, are shown in columns 1,2 and 4 respectively of Fig. 14. The evolution of delaminations at the interface $\left(0^{\circ} / 45^{\circ}\right)$ of ply $\mathrm{C}$ is also given in column 3 of this figure. The outer ply splits with two matrix cracks initiating early at the hole edge and propagating in the direction of loading. Delamination follows the same geometry in a confined area before structural failure. At this stage, the outer ply fibre failure occurs later but more suddenly (many elements are destroyed at the same time) than that of the inner ply. Therefore, for ply D, as for plies A and B, there is a brutal first failure then gradual failure of the fibre. In addition, as for the "Q-isotropic 2" laminate, structural failure is caused by the failure of a some of the $0^{\circ}$ ply fibres out of the net section. In contrast, the outer ply has two splits, which seem to delay local failure of fibres by locally reducing the effects of stress concentration near the hole and redirecting stress flow. So, for this second quasi-isotropic laminate, it is logical that the structural failure should occur at the same load as in the previous quasi-iso laminate. The drop in force is smaller for this second layup as net sections of the two outer plies are almost intact. When the load increases, the fibres of the D-type ply gradually break with an angle of $45^{\circ}$. The final failure of the outer plies is more sudden but more delayed, which explains why, experimentally, the UTS of this layup is greater than the other quasi-isotropic layup (see Fig. 7). Regarding delaminated areas, it is noted that, for $0^{\circ} / 45^{\circ}$ interfaces located just below the outer $0^{\circ}$, the shape follows the cracked area of the matrix (see Fig. 14). The calculation also shows that, for this laminate, matrix cracking occurs earlier than delamination. Other interfaces present smaller delaminated areas with shapes that are mainly similar to the matrix cracked areas of $\pm 45^{\circ}$ plies and identical to those observed on laminate q-iso- 2 .

\subsubsection{Failure scenario of Oriented 2 laminate}

This configuration creates a new loading environment for $0^{\circ}$ plies (ply type E, Fig. 12$)$. Two $0^{\circ}$ plies are superposed $(0.254 \mathrm{~mm}$ thick instead of $0.127 \mathrm{~mm}$ ) and the interfaces are different: $0^{\circ} /$ $-45^{\circ}$ and $0^{\circ} / 90^{\circ}$. This new environment results in a new process of matrix cracking, where splitting is coupled with transverse propagation. However, unlike the situation for single ply $\mathrm{C}$, the 


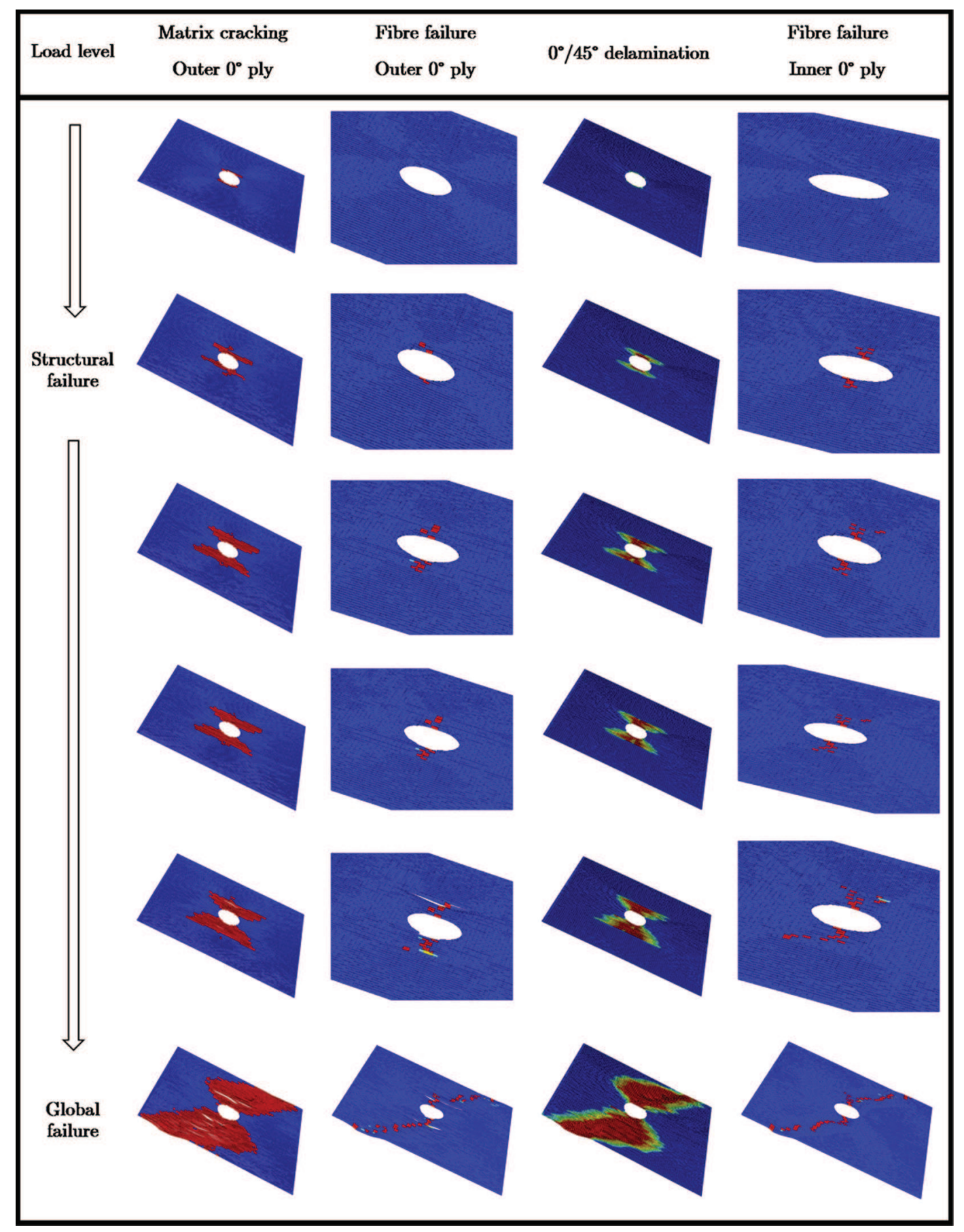

Fig. 14. Failure scenario for q-iso 1 . Columns 1 and 2 respectively: matrix cracking and fibre failure in outer $0^{\circ}$ ply. Columns 3 : delamination at interfaces $0^{\circ} / 45^{\circ}$ (outer ply) Colum 4: fibre failure of $0^{\circ}$ inner ply.

splitting is much more developed, i.e. longer and narrower, before structural failure (Fig. 15, column 1). Some fibres are broken in the vicinity of the hole edge but the damage does not propagate until structural failure occurs (Fig. 15, column 2). At structural failure, all types of damage (matrix cracking, delamination at the interfaces of $0^{\circ}$ plies, and fibre breakage, Fig. 15) increase suddenly. The net section is then reduced to about $50 \%$, which causes a decrease in the load. As loading continues up to UTS, matrix cracking propagates to the free edges and fibre breakage occurs randomly. Once again, during the damage process, the shape of the delamination of the $0^{\circ} / 90^{\circ}$ interface exactly follows the cracked region of the $0^{\circ}$ plies. In column 4 , the evolution of the delamination of the first interface near the outer surface is also shown. An X shape is observed with a very limited extent. This configuration is compatible with the fracture surface at $45^{\circ}$ of the outer plies visible in Fig. 9(a).

\subsubsection{Failure scenario of Oriented 1 laminate}

For this laminate, there is a new loading configuration for the $0^{\circ}$ plies (plies type F and G, Fig. 12). For plies $\mathrm{F}$ the thickness is even greater than previously $(2 \times 0.18$, i.e. $0.36 \mathrm{~mm})$. Moreover, these plies are located just under the outer surface of the laminate and have $-45^{\circ} / 0^{\circ} / 0^{\circ} / 45^{\circ}$ interfaces (similarly to plies A, B and D). Ply $\mathrm{G}$ is located deeper in the laminate and its $-45^{\circ} / 0^{\circ} / 90^{\circ}$ interfaces are similar to those of ply E. 


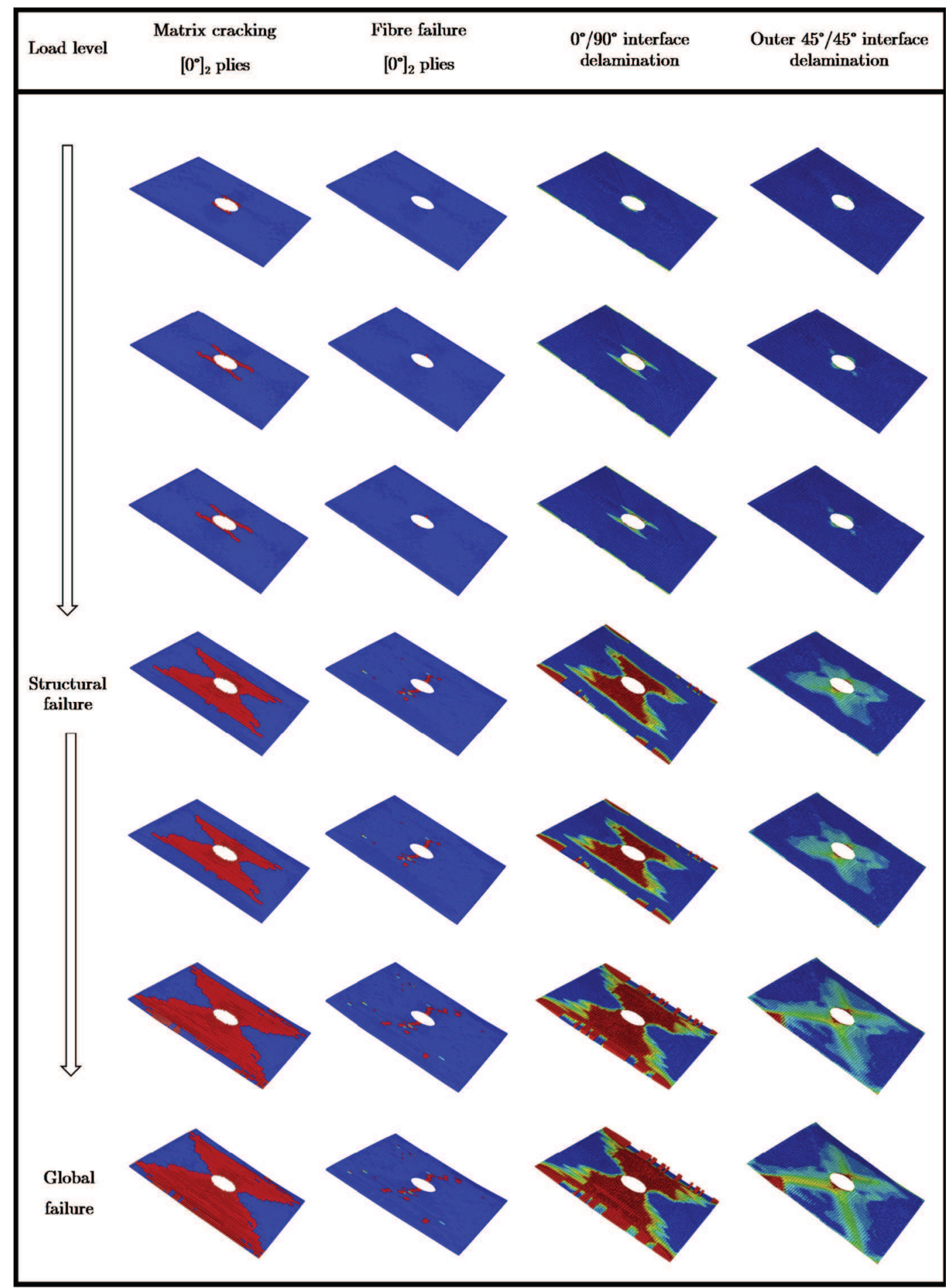

Fig. 15. Failure scenario for Oriented 2 . Column 1 and 2 respectively: matrix cracking and fibre failure in $0^{\circ}$ plies. Column 3 : delamination at interfaces $\left[0^{\circ}\right]_{2} / 90^{\circ}$. Column 4 : delamination at outer interface $45^{\circ} /-45^{\circ}$.

For both types of $0^{\circ}$ plies, the first damages are longitudinal splittings (Fig. 17, columns 1 and 3). For the inner ply, G, splitting extends over a fairly short length, initially without fibre failure. When the load increases, matrix cracking propagates transversely, causing the failure of some elements of fibre on less than about $10 \%$ of the net section (Fig. 16, pre-failure). This failure is visible on a zoom of the stress-strain curve provided by the model (Fig. 16). However, this damage is not sufficient to cause structural failure. When the load increases again, the transverse propagation of transverse cracking continues, accompanied by the gradual failure of the fibre of ply G. Then a stage of damage stabilization of this ply is reached. Nevertheless, the final failure is not caused directly by this ply.

For ply F, there is crack propagation with thin splitting along the total length of the specimen (Fig. 17, column 1). The presence of such splitting has the effect of strongly reducing the stresses on fibre elements near the hole. Thus, the integrity of these plies is kept when the load increases. At UTS, there is a very sudden break of 


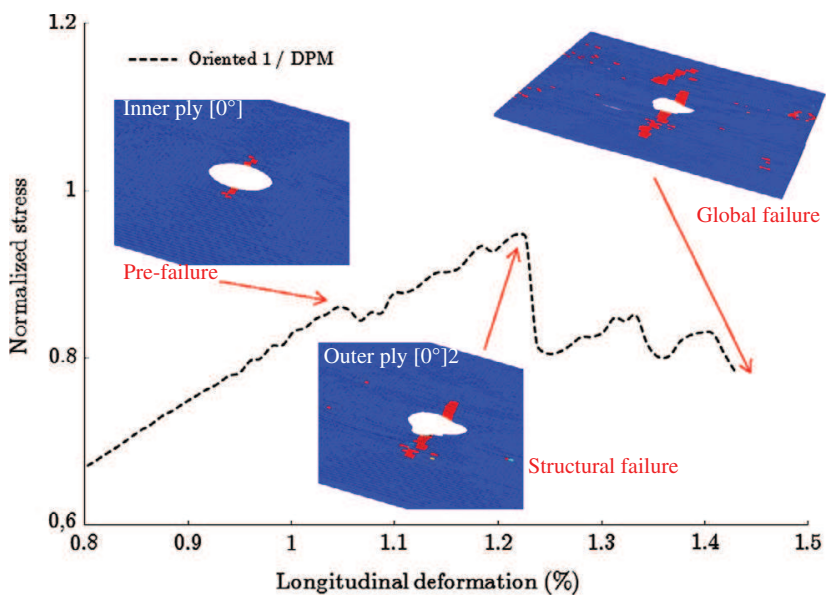

Fig. 16. Fibre failure at structural failure and global failure of Oriented 1 layup. these outer $0^{\circ}$ plies (Fig. 16), causing first structural failure and ultimately the overall failure. The damage is not symmetrical in this case, probably because of numerical dynamic effects. However, this dispersion is consistent with the post-mortem pattern.

The process of delamination of the $45^{\circ} /-45^{\circ}$ interface (Fig. 17 , column 4) is also provided. The process involved here is very different from that observed on the Oriented 2 laminate, which was just below the outer surface of the laminate. Here, delamination is initiated at the hole edge but also at the free edges.

\section{Conclusion}

This paper presents the direct extension of the DPM approach to open hole tensile tests, without modification. The only adjustment was to refine the mesh near the hole. The capacity of the DPM was evaluated on an industrial benchmark of four very different laminates. Good agreement was found between the numerical and experimental results, with good prediction of ultimate Tensile stresses and failure patterns. The numerical model was used to make a refined analysis of the damage scenario for each laminate.

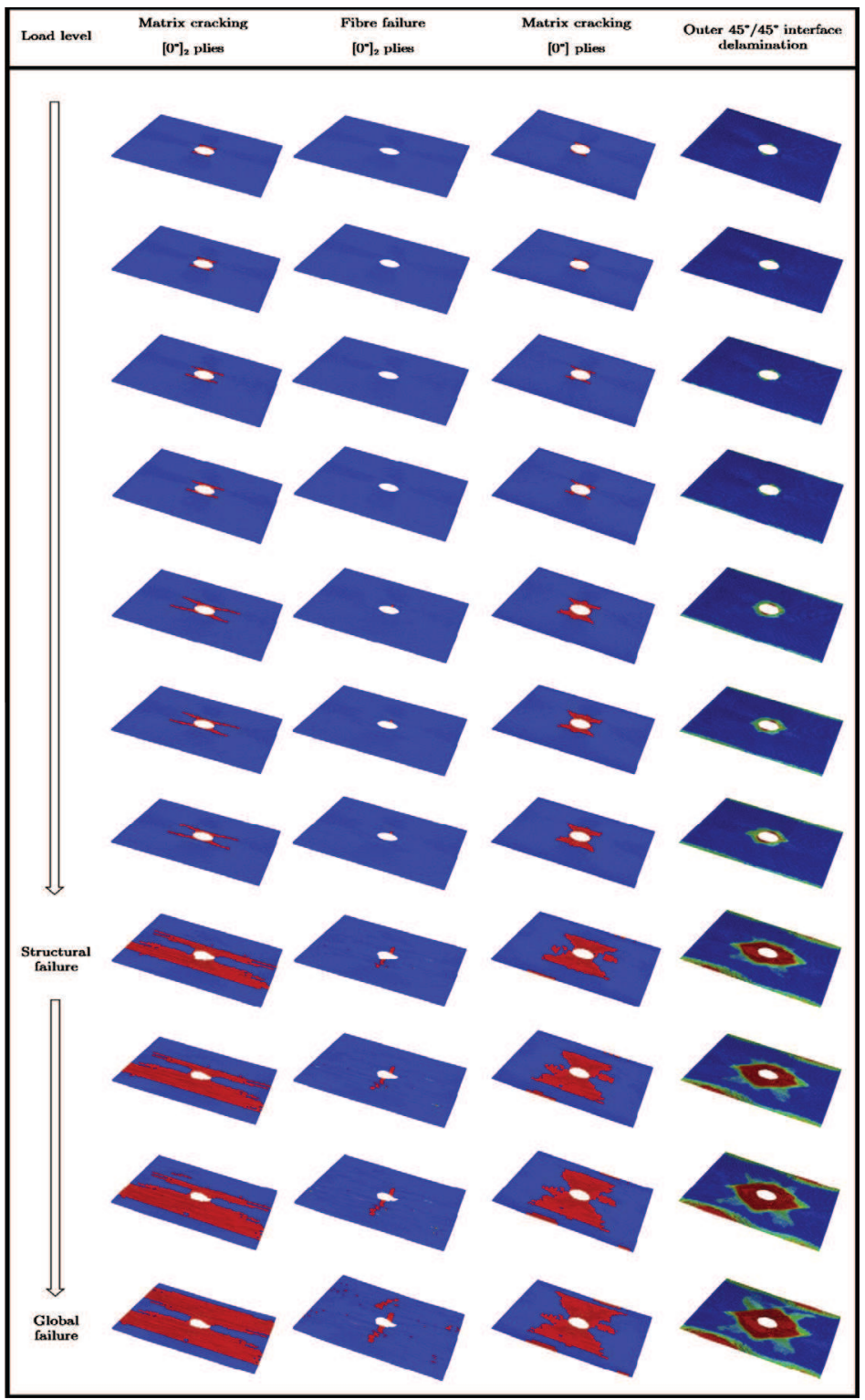

Fig. 17. Failure scenario for Oriented 1 . Columns 1 and 2 respectively: matrix cracking and fibre failure in $\left[0^{\circ}\right]_{2}$ outer plies. Column 3 : matrix cracking for inner $0^{\circ}$ ply. Column 4: delamination at outer interface $45^{\circ} \%-45^{\circ}$. 
The importance of the position of $0^{\circ}$ plies in the thickness of the laminate was thus demonstrated. In particular, it was shown that the $0^{\circ}$ plies placed near or at the outer surface split more easily, so the stress concentration near the hole diminished and the final failure was delayed. Therefore, it can be said that the $0^{\circ}$ plies are protected inside the laminate.

The model also showed that the general patterns of damage of $45^{\circ}$ and $90^{\circ}$ plies adjacent to $0^{\circ}$ plies were generally quite similar, with a difference only when the $0^{\circ}$ plies split, thus modifying local stress fields. We also found that matrix cracking in a ply always occurred slightly before delamination at adjacent interfaces. It is likely that local scenarios are identical to those identified in impact [8]. This also explains, a posteriori, why the approach gave good results: the model has good ability to address the inter- and intralaminar coupling.

The robustness of the model should now be tested on a more comprehensive benchmark applying the same philosophy as Rivallant et al. [11]. The authors also suggest extending the validation of this approach to more complex phenomenology of failure, as in the case of offset failure in a filled hole in compression [28], and to composite structures under complex loading [29].

\section{Acknowledgements}

The academic authors thank Airbus Operation S.A.S. for its support, especially Clément Chirol and Bernard Bourthoumieux.

\section{References}

[1] Hallett SR, Green BG, Jiang W-G, Cheung KH, Wisnom MR. The open hole tensile test: a challenge for virtual testing of composite. Int J Fract 2009;158:169-81.

[2] MIL-HDBK-17. Military handbook, polymer matrix composites. US Department of Defense; 1994.

[3] Wisnom MR, Hallett SR. The role of delamination in strength, failure mechanism and hole size effect in open hole tensile tests on quasi-isotropic laminates. Compos Part A 2009;40:335-42.

[4] Hu Y-L, Yu Y, Wang H. Peridynamic analytical method for progressive damage in notched composite laminates. Compos. Struct. 2014;108:801-10.

[5] Madenci E, Oterkus E. Peridynamic theory and its applications. Springer; 2013.

[6] Abisset E, Daghia F, Ladevèze P. On the validation of a damage mesomodel for laminated composites by means of open-hole tensile tests on quasi-isotropic laminates. Compos Part A 2011;42:1515-24.

[7] Van der Meer FP, Sluys LJ. Continuum models for the analysis of progressive failure in composite laminates. J Compos Mater 2009;43:2131-56.

[8] Bouvet C, Castanié B, Bizeul M, Barrau J-J. Low velocity impact modelling in laminate composite panels with discrete interface elements. Int J Solids Struct 2009;46(14-15):2809-21.
[9] Adam L, Bouvet C, Castanié B, Daidié A, Bonhomme E. Discrete ply model of circular pull-through test of fasteners in laminates. Compos Struct 2012;94(10): 3082-91.

[10] Hongkarnjanakul N, Bouvet C, Rivallant S. Validation of low velocity impact modelling on different stacking sequences of CFRP laminates and influence of fibre failure. Compos Struct 2013;106:549-59.

[11] Rivallant S, Bouvet C, Hongkarnjanakul N. Failure analysis of CFRP laminates subjected to compression after impact: FE simulation using discrete interface elements. Compos Part A 2013;55:83-93.

[12] Bouvet C, Rivallant S, Barrau J-J. Low velocity impact modeling in composite laminates capturing permanent indentation. Compos Sci Technol 2012;72(16): 1977-88.

[13] Prabhakar P, Waas AM. A novel continuum-decohesive finite element for modeling in-plane fracture in fiber reinforced composites. Compos Sci Technol 2013;83:1-10.

[14] Moës N, Belytschko T. Extended finite element method for cohesive crack growth. Eng Fract Mech 2002;69(7):813-33.

[15] Van der Meer FP, Sluys LJ, Hallett SR, Wisnom MR. Computational modeling of complex failure mechanisms in laminates. J Compos Mater 2012;46(5): 603-23.

[16] Van der Meer FP, Sluys LJ. A phantom node formulation with mixed mode cohesive law for splitting in laminates. J Fract 2009;158(2):107-24.

[17] Van der Meer FP, Dávila CG. Cohesive modeling of transverse cracking in laminates under in-plane loading with a single layer of elements per ply. Int J Solids Struct 2013;50:3308-18.

[18] Iarve EV. Mesh independent modeling of cracks by using higher order shape functions. Int J Numer Methods Eng 2003;56(14):869-82.

[19] Iarve EV, Gurvich MR, Mollenhauer DH, Rose CA, Davilà CG. Mesh independent matrix cracking and delamination modeling in laminated composites. Int J Numer Methods Eng 2011;88(8):749-73.

[20] Swinderman MJ, Iarve EV, Brockman RA, Mollenhauer DH, Hallet RH. Strength prediction in open hole composite laminates by using discrete damage modeling. AIAA J 2013;51(4):936-45.

[21] Hashin Z, Rotem A. A fatigue failure criterion for fiber-reinforced materials. J Compos Mater 1973;7:448-64.

[22] Pinho ST, Robinson P, Iannucci L. Fracture toughness of the tensile and compressive fibre failure modes in laminated composites. Compos Sci Technol 2006;66:2069-79.

[23] Bazant ZP, Oh BH. Progressive crack and band theory for fracture of concrete. Mater Struct 1983;16:155-77.

[24] Lapczyk I, Hurtado JA. Progressive damage modelling in fiber-reinforced materials. Compos Part A 2007;38:2333-41.

[25] Raimondo L, Iannucci L, Robinson P, Curtis PT. A progressive failure model for mesh-size-independent FE analysis of composite laminates subject to lowvelocity impact damage. Compos Sci Technol 2012;72:624-32.

[26] Shi Y, Swait T, Soutis C. Modelling damage evolution in composite laminates subjected to low velocity impact. Compos Struct 2012;94(9):2902-13.

[27] Hexply ${ }^{\circledR}$ product data. <www.hexcel.com/resources/datasheets>

[28] Castanié B, Crézé S, Risse L, Barrau JJ, Lachaud F. Experimental analysis of failures in filled hole compression tests of carbon/epoxy laminate. Compos Struct 2010;92(5):1192-9.

[29] Castanié B, Barrau J-J, Jaouen J-P, Rivallant S. Combined shear/compression structural testing of asymmetric sandwich structures. Exp Mech 2004;44(5): $461-72$. 